\title{
R elação entre mercado de terras, crescimento econômico e insegurança fundiária explicada por um modelo a "geração imbricada"
}

\author{
CLAUDIO ARAUJO \\ CATHERINE ARAUJO BONJEAN \\ JEAN-LOUIS COMBES \\ PASCALE COMBES MOTEL*
}

Relationship between the land market, economic growth and land insecurity explained by an overlapping model. In this paper, we analyze the relationship between the land market failures and the economic growth in Brazil, starting from an overlapping model including two sectors: agricultural and industrial. The land is both a specific factor for agriculture and an asset that can be substituted to the capital used in industry. The trade-off between land and capital holding depends, among other factors, on the transaction costs on the land market. These costs result from land insecurity and generate a decrease in the land price that favors capital accumulation. Two assumptions follow from our model: one the one hand, land insecurity has a negative effect on the land price; one the other hand it has a positive effect on economic growth. These two hypotheses are tested on panel data for Brazilian Federation. The econometric results do not reject our hypothesis.

Key-words: land price, trade off capital-land, overlapping model.

JEL classification: O41, Q15, O54.

Este artigo coloca em evidência a relação existente entre o mercado fundiário e o crescimento econômico. A análise é realizada no caso do Brasil, onde os altos índices de concentração fundiária e a insegurança jurídica, devido a imperfeição dos direitos de propriedade, é fonte de conflitos violentos pelo acesso à

\footnotetext{
* Respectivamente, professor - pesquisador, pesquisadora CNRS, professor-pesquisador e professorapesquisadora do Centre D’Études et de Recherches sur le Développement International, Université d'Auvergne, França (e-mails: c.araujo@u-clermont1.fr, c.araujo-bonjean@u-clermont1.fr, j-1.combes@u-clermont1.fr e p.motel_combes@u-clermont1.fr. Submetido: dezembro 2004; aceito: agosto 2005.
} 
terra (Alston \& alli, 1999). Assim, a história do Brasil é marcada por movimentos importantes de ocupação de propriedades rurais por produtores sem-terra e tentativas malogradas de redistribução fundiária. No entanto, mesmo se a reforma agrária é um objetivo essencial dos poderes públicos, a literatura econômica mostra paradoxalmente que existe uma relação negativa entre desenvolvimento do mercado de terras e o crescimento econômico.

Geralmente, a finalidade dos programas de reforma agrária é obter uma alocação eficiente de terras entre os diferentes utilizadores potenciais. Esses programas são justificados por razões de eficiência e igualdade (De Janvry \& alli, 2001; Deininger, 1999, 2003). Assim, a distribuição de terras em benefício de pequenos lavradores excluídos do mercado de créditos permite contornar as restrições de liquidez ligadas à aquisição de um ativo indivisível. Ela possibilita igualmente, às categorias desfavorizadas de agricultores sem terras, um emprego mais eficaz da força de trabalho e dos ativos produtivos em suas próprias terras. A redistribuição de terras permite também o aumento da produtividade agrícola, devido a existência da relação inversa entre o tamanho da propriedade rural e sua produtividade (Binswanger, Deininger \& Feder, 1995; Junqueira Assunção, 2003; Junqueira Assunção e Ghatak, 2003). Além disso, um maior seguro dos direitos de propriedade favorece geralmente o investimento e, por conseguinte, o crescimento agrícola, apesar deste ponto ser controvertido na literatura econômica (e.g. Brasselle, Gaspart \& Platteau, 2002; Banerjee \& Ghatak, 2004). Esses argumentos microeconômicos são reforçados pelas análises macroeconômicas que mostram uma relação positiva entre a redução da desigualdade na distribuição de ativos e o crescimento econômico (Birdsall \& Londono, 1997; Deininger \& Squire, 1998; Persson \& Tabellini, 1992). Por conseguinte, a redistribuição dos ativos rurais é, em geral, considerada como um meio de lutar contra a pobreza rural e, favorece, dessa maneira, o crescimento econômico.

Entretanto, desenvolvimentos recentes da literatura moderam esses argumentos positivos. Em um modelo, onde a terra é, ao mesmo tempo, um fator fixo de produção e um ativo entrando no portofólio dos agentes econômicos, a arbitragem em benefício do ativo rural conduz a um investimento em capital e à um nível de renda mais baixo (Eaton, 1987). Ou seja, a utilização da poupança na compra de terras implica uma deterioração do ativo acumulativo que é a fonte do crescimento econômico. Neste tipo de análise, a concentração de terras, que pode mesmo bloquear a emergência do mercado fundiário, favorece o investimento em capital e o crescimento (Drazen \& Eckstein, 1988). Da mesma maneira, supondo-se que a detenção de terras produz uma certa utilidade para as famílias pelos serviços que ela fornece (prestígio, serviços imobiliários ...), o efeito de evicção do capital conduz à um baixo nível de renda (Deaton \& Laroque, 2001). Assim, de acordo com essas análises, uma reforma agrária que procura distribuir títulos de terras, que podem ser trocados no mercado, tem um impacto negativo no crescimento econômico.

O modelo teórico, desenvolvido na primeira seção deste artigo, baseia-se numa condição de arbitragem entre o ativo fundiário e o capital empregado no se- 
tor manufaturado. A relevância dessa formulação é considerar os custos de transação específicos ao ativo fundiário resultantes de definições imperfeitas e não transparentes dos direitos de propriedade. Esses custos podem impedir a aquisição de direitos de propriedade, pois, compradores potenciais de terras são dissuadidos por causa da pressão e do custo excessivo existente na proteção de direitos fundiários. Esse fato é conforme a realidade brasileira, onde a não transparência de direitos de propriedade causa violentos conflitos pelo acesso à terra. Mostra-se, assim, que o efeito de evicção do capital pelo ativo fundiário diminui com a insegurança rural. Duas hipóteses procedem desta formulação: um efeito negativo da insegurança rural sobre o preço da terra e um efeito positivo sobre o crescimento econômico. Essas hipóteses são testadas, na segunda seção, usando instrumentos da econometria de painel. O painel é composto de vinte sete unidades da federação e seis períodos $(1970,1975,1980,1985,1990$ e 1995). As implicações do modelo para a formulação de políticas fundiárias são apresentadas na última seção.

\section{CONDIÇÃO DE ARBITRAGEM ENTRE TERRA E CAPITAL E MODELO A “GERAÇÃO IMBRICADA”}

O modelo teórico utilizado é um modelo a "geração imbricada" (overlapping model), inspirado de Eaton (1987) e de Drazen e Eckstein (1988), comportando dois setores e três fatores de produção. A terra é um fator de produção específico ao setor agrícola e uma alternativa de poupança, da mesma maneira que são os títulos da dívida pública (Diamond, 1965), a moeda (Samuelson, 1958), ou o investimento imobiliário (Deaton \& Laroque, 2001).

A população, composta de $L$ famílias proprietárias dos fatores de produção e, por conseguinte, das empresas, é suposta estacionária. As famílias e as empresas consumem e produzem durante dois períodos $(t$ e $t+1)$. No período $t$, uma família oferece uma unidade de trabalho no setor manufaturado ou agrícola e, distribui sua renda entre o consumo e a poupança. A poupança é investida na empresa do setor manufaturado ou agrícola. O patrimônio da família serve a financiar seu próprio consumo no período futuro $(t+1)$. Ou seja, as famílias não dispõem de nenhuma riqueza material inicial e não deixam nenhuma herança às gerações futuras.

\section{0 setor produtivo}

A economia é constituída de dois setores: manufaturados e agrícola. O primeiro produz um bem em quantidade $\mathrm{M}$. O segundo produz conjuntamente um bem em quantidade $A$ e um serviço de segurança fundiária. Para o consumo das famílias, os dois bens são considerados como substitutos perfeitos e servem de numerário: seus preços são iguais e fixos, ou seja a razão é 1. Supõem-se também que os mercados são concorrentes. 
O setor manufaturado utiliza os fatores capital $(\mathrm{K})$ e trabalho $\left(\mathrm{L}^{\mathrm{m}}\right)$. O setor agrícola utiliza os fatores terra $(T)$ e trabalho $\left(L^{a}\right)$. O trabalho é perfeitamente móvel entre os setores e as famílias não suportam nenhum custo ligado à alocação setorial do trabalho. Cabe salientar que a oferta de terras é considerada fixa a cada período, sendo assim independente do tempo. As tecnologias de produção, cujos rendimentos de escala são constantes, estão descritas pelas seguintes funções de produção:

$$
\begin{aligned}
& M_{t}=M\left(K_{t}, L_{t}^{m}\right) \\
& A_{t}=A\left(T, L_{t}^{a}\right)
\end{aligned}
$$

Com relação à essas funções de produção, admite-se as hipóteses seguintes: elas são contínuas e diferenciadas, no mínimo, duas vezes; as produtividades dos fatores são positivas e decrescentes e as condições de Inada são verificadas. Além disso, o impacto do trabalho nas produtividades marginais do capital e da terra não é negativo. O preço do capital é igualmente o numerário, pois o bem produzido pelo setor de manufaturas serve indiferentemente ao consumo e ao investimento. A taxa de amortização do capital é negligenciada.

A terra, sendo considerada como fator fixo de produção e independente do tempo, não é um fator acumulativo como o capital que é um fator produtivo e utilizado no setor manufaturado. Logo, a produtividade marginal da terra depende, unicamente, do nível de trabalho utilizado no setor agrícola.

$O$ custo de transação relacionado à aquisição de terras, $C_{t}$, é dado pela seguinte função:

$$
\mathrm{C}_{\mathrm{t}}=\mathrm{C}\left(\mathrm{p}_{\mathrm{t}} \mathrm{\top} ; \alpha_{\mathrm{t}}\right)
$$

onde, $p_{t} T$ representa o valor das transações; $p_{t}$ o preço da terra e $a_{t}$ a insegurança fundiária.

O custo de transação é crescente de acordo com o valor das transações $\left(\mathrm{p}_{t} \top\right)$ e a insegurança fundiária $\left(\alpha_{t}\right)$. Esse custo é causado pela falta de garantia jurídica e pela dificuldade, existente no Brasil, a respeitar os direitos de propriedade agrária. Para uma empresa agrícola, o risco de expropriação ou, de ocupação ilegal de terras por ocupantes, acarreta "custos de proteção de direitos de propriedade", chamados também custos de exclusão. Deve-se salientar que, no Brasil, o risco de expropriação é bastante importante tanto para latifundiários, que podem ter parcelas de suas terras invadidas, como para minifundiários, que podem ser expulsos por proprietários influentes. Para se proteger contra o risco de expropriação, ou de ocupação, os proprietários devem financiar um "serviço de segurança fundiária"; pagando, por exemplo, os ocupantes para que eles deixem suas terras; ou, como atesta vários fatos da realidade brasileira, contratar o serviço de jagunços. 
Quando os direitos de propriedade são perfeitamente respeitados, ou seja, quando as regras sobre a propriedade de terras são transparentes, o custo de transação é nulo, $\mathrm{C}\left(\mathrm{p}_{\mathrm{t}} \mathrm{T} ; 0\right)=0$. 0 custo marginal, $\partial \mathrm{C} / \partial \mathrm{T}$, é compreendido entre $0 \mathrm{e}$ 1, e aumenta de acordo com $\alpha_{t}$ (a derivada cruzada é positiva: $\partial^{2} \mathrm{C} / \partial \mathrm{T} \partial \mathrm{a}>0$ ).

A empresa representativa do setor manufaturado maximiza o lucro intertemporal anticipado, $\mathrm{V}^{\mathrm{m}}$, definido da seguinte maneira:

$$
V^{m} \equiv-\left(K_{t+1}-K_{t}\right)+\frac{1}{1+E_{t} r_{t+1}} E_{t}\left(M\left(K_{t+1}, L_{t+1}^{m}\right)-W_{t+1} L_{t+1}^{m}+K_{t+1}\right)
$$

$E_{t}$ é o operador de esperança matemática condicional à informação disponível em $t ; w_{t}$ representa a taxa do salário real na data $t ; e, r_{t}$ a taxa de juros reais. $\mathrm{O}$ capital inicial $\mathrm{K}_{\mathrm{t}}$ pertencente à primeira geração (chamada "antigos") é dado, e o capital final $\mathrm{K}_{\mathrm{t}+2}$ é nulo, pois a empresa, que pertence aos "antigos" no período $t+1$, revende integralmente seu capital produtivo no final do período $t+1$. Isto é, no período t, as empresas do setor de manufaturas escolhem o nível de seus investimentos, portanto o capital futuro. No período $t+1$, elas produzem e, em seguida, revendem a totalidade de seus ativos. Assim, as variáveis de controle são $L^{\mathrm{m}}{ }_{\mathrm{t}+1}$ e $\mathrm{K}_{\mathrm{t}+1}$.

A empresa representativa do setor agrícola maximiza o lucro intertemporal antecipado, $\mathrm{V}^{\mathrm{a}}$, que leva em conta a mais ou menos valia fundiária:

$$
\mathrm{V}^{\mathrm{a}} \equiv-\left(\mathrm{p}_{\mathrm{t}} \mathrm{T}+\mathrm{C}\left(\mathrm{p}_{\mathrm{t}} \mathrm{T} ; \alpha_{\mathrm{t}}\right)\right)+\frac{1}{1+\mathrm{E}_{\mathrm{t}} \mathrm{r}_{\mathrm{t}+1}} \mathrm{E}_{\mathrm{t}}\left(\mathrm{A}\left(\mathrm{T}, \mathrm{L}_{\mathrm{t}+1}^{\mathrm{a}}\right)-\mathrm{w}_{\mathrm{t}+1} \mathrm{~L}_{\mathrm{t}+1}^{\mathrm{a}}+\mathrm{p}_{\mathrm{t}+1} \mathrm{~T}\right)
$$

No período t, a empresa agrícola compra a terra que se tornará produtiva em $t+1$. Ela suporta, além disso, o custo de transação fundiário (equação 2). Em $t+1$, ela produz e, em seguida, revende a terra aos "antigos". As variáveis de controle são $L^{a}{ }_{t+1}$ e $T$.

A maximização dos lucros intertemporais antecipados induzem às seguintes condições necessárias de primeira ordem: ${ }^{1}$

$$
\begin{aligned}
& E_{t} \frac{\partial M_{t+1}}{\partial K_{t+1}}=E_{t} r_{t+1} ; K_{t+1}-K_{1}>0 \\
& E_{t} \frac{\partial M_{t+1}}{\partial L_{t+1}}=E_{t} r_{t+1} ; L_{t+1}^{m}>0 \\
& \frac{E_{t} p_{t+1}-p_{t}}{p_{t}}+\frac{1}{p_{t}} E_{t} \frac{\partial A_{t+1}}{\partial T}=E_{t} r_{t+1}+\frac{\partial C_{t}}{\partial T} ; p T_{i}>0
\end{aligned}
$$

\footnotetext{
${ }^{1}$ As condições suficientes de segunda ordem são satisfeitas. Na hipótese de expectativas perfeitas, os operadores de esperança matemática podem ser omitidos.
} 


$$
E_{t} \frac{\partial A_{t+1}}{\partial L_{t+1}^{a}}=E_{t} W_{t+1} \quad ; \quad L_{t+1}^{a}>0
$$

Supõe-se que as hipóteses necessárias à aplicação do teorema do envelope são respeitadas. Em particular, as condições de segunda ordem e a hipótese de um impacto positivo da insegurança fundiária sobre o custo marginal de transação i.e. $\partial^{2} \mathrm{C} / \partial \mathrm{T} \partial \alpha>0, \forall \alpha$ compreendido entre 0 e 1 são respeitados.

A equação (5) significa que o capital é remunerado de acordo com sua produtividade marginal. Isto é,conforme a hipótese de concorrência pura e perfeita.

Um acréscimo do capital no setor manufaturado aumenta a produtividade marginal do trabalho e, por conseguinte, a taxa de salário da economia. O equilíbrio do mercado de trabalho é restaurado por um fluxo das famílias do setor agrícola em direção ao setor manufaturado (equações (6) e (8)). A acumulação produtiva conduz à uma migração da mão-de-obra rumo ao setor de manufaturas.

A equação (7) é interpretada como uma condição de arbitragem entre a terra e o capital. O termo da direita representa o custo de oportunidade de detenção da terra. Ele é composto da taxa de juros reais antecipado somada ao custo marginal nas transações fundiária. O termo da esquerda representa o ganho marginal antecipado devido à detenção de uma unidade suplementar de terra. Ele é representado pela soma da taxa de variação antecipada do preço da terra e de sua produtividade marginal antecipada.

$\mathrm{Na}$ ausência de bolhas especulativas no preço da terra, a taxa de variação antecipada do preço da terra é nulo. Assim, a condição de primeira ordem (7) torna-se uma equação de equilíbrio do preço da terra. $\mathrm{O}$ valor de equilíbrio do preço da terra é dado da seguinte forma:

$$
p_{t}^{*}=\frac{E_{t} \frac{\partial A_{t+1}}{\partial T}}{E_{t} r_{t+1}+\frac{\partial C_{t}}{\partial T}}
$$

Resulta-se dessa equação uma primeira hipótese a ser testada.

H ipótese 1: um acréscimo da insegurança fundiária diminui o preço corrente da terra.

Essa hipótese resulta da relação existente entre a insegurança fundiária e o custo marginal de transação. Portanto, um acréscimo da insegurança fundiária $a_{t}$ aumenta o custo marginal de transação $\left(\partial C_{t} / \partial T\right)$, e, por conseguinte, o custo de oportunidade de detenção da terra. Resulta-se, como visto na equação (7a), um aumento do preço da terra. Se a insegurança fundiária é nula $(\alpha=0)$, o custo de oportunidade de detenção da terra não é elevado; por conseguinte, o preço da terra é alto. Caso contrário, se a insegurança fundiária é máxima $(\alpha=1)$, o custo de oportunidade de detenção da terra é, ceteris paribus, máximo, conduzindo assim à diminuição do preço da terra. 
Nota-se que o respeito da condição de equilíbrio (7) implica um aumento do rendimento antecipado. Supondo-se que o preço da terra reflita seu valor fundamental, a taxa de variação antecipada do preço da terra é nula. Em conseqüência, o aumento do rendimento antecipado da terra pode ser obtido pela migração da mão-de-obra do setor de manufaturas ao setor agrícola ou, provavelmente, pela diminuição da demanda de terras que conduz à uma diminuição do preço corrente.

Além disso, um aumento do capital, no setor manufaturado, diminui sua produtividade marginal, ou seja, a taxa de juros e, portanto, o custo de oportunidade de detenção de terra. O respeito da condição de arbitragem (7) supõe então uma diminuição do rendimento antecipado da terra. Isto é possível, como assinalado, pelo fluxo migratório do setor agrícola ao setor manufaturado ou pelo aumento do preço corrente da terra. Efetivamente, no período t, a procura de terras das empresas agrícolas é forte, conduzindo assim a um aumento do seu preço corrente, pois a oferta de terras é fixa.

\section{O planejamento do consumo}

O horizonte de planejamento do consumo de uma família é de dois períodos: $\mathrm{t}$ e $\mathrm{t}+1$. Seja $\mathrm{x}_{1, \mathrm{t}}$ e $\mathrm{x}_{2, \mathrm{t}+1}$ respectivamente o consumo da família da primeira geração, chamada "jovem", e da família da segunda geração, chamada "antiga". A cesta de consumo é composta de bens manufaturados e agrícolas. O serviço de segurança fundiária é consumido uma única vez pela família no período t. Durante o período de planejamento presente (t), supõe-se que a oferta de trabalho da família é inelástica. Ou seja, não existe arbitragem entre trabalho e lazer.

A função de utilidade intertemporal da família é dada da seguinte forma:

$$
\mathrm{U} \equiv \mathrm{U}\left(\mathrm{x}_{1, \mathrm{t}}, \mathrm{x}_{2, \mathrm{t}+1}\right)
$$

Supõe-se que a função de utilidade é aditiva separável no tempo; a taxa de depreciação é constante; e, as utilidades marginais atuais são positivas e não crescentes. A família respeita as seguintes restrições orçamentárias no período de planejamento:

$$
\left\{\begin{array}{l}
x_{1, t}=w_{t}-s_{t} \\
x_{2, t+1}=\left(1+E_{t} r_{t+1}\right) s_{t}
\end{array}\right.
$$

onde $\mathrm{s}_{\mathrm{t}}$ representa a poupança.

\footnotetext{
${ }^{2}$ Como na maioria dos modelos da geração imbricada, a expressão da restrição orçamentária intertemporal estabelece que a riqueza da família é igual ao salário corrente. As condições suficientes de segunda ordem são satisfeitas
} 
As riquezas materiais, iniciais e finais, são nulas. As condições necessárias de primeira ordem do programa do consumidor estabelecem a função de poupança na data $t:^{2}$

$$
s_{t}=s\left(w_{t}, E_{t} r_{t+1}\right)
$$

A propensão marginal a poupar as rendas do trabalho é estritamente compreendida entre 0 e 1 . Um acréscimo das rendas salariais conduz a um aumento de menor importância da renda permanente e, portanto, a um aumento da poupança. Esse resultado é uma conseqüência da ausência de rendas do trabalho durante o segundo período de vida. Se o efeito de substituição é superior ao efeito de renda, as taxas de juros antecipadas afetarão positivamente a poupança.

$\mathrm{Na}$ hipótese onde a função de utilidade é logarítmica (elasticidade de substituição intertemporal do consumo unitária), no período de planejamento, os efeitos de substituição e de renda se compensam. A função de poupança (11) dependerá, então, unicamente do salário corrente.

\section{A dinâmica da economia}

O estoque de capital no período $t+1$ somado ao valor da terra é igual a poupança dos "jovens": ${ }^{3}$

$$
\mathrm{K}_{\mathrm{t}+1}+\mathrm{p}_{\mathrm{t}} \mathrm{T}=\mathrm{s}\left(\mathrm{w}_{\mathrm{t}}\right) \mathrm{L}
$$

Segundo as equações (6) e (8), o salário $\left(\mathrm{w}_{\mathrm{t}}\right)$ depende do estoque de capital do mesmo período. Estabelece-se então, no caso geral, a dinâmica do capital da seguinte forma:

$$
\mathrm{K}_{\mathrm{t}+1}+\mathrm{p}_{\mathrm{t}} \mathrm{T}=\mathrm{D}\left(\mathrm{K}_{\mathrm{t}}\right) \mathrm{L} ; \mathrm{D}^{\prime}>0 \text { e } \mathrm{D}^{\prime \prime}<0
$$

A função $D\left(K_{t}\right)$ estabelece uma relação de recorrência unindo o capital corrente ao capital futuro. As propriedades de $\mathrm{D}\left(\mathrm{K}_{\mathrm{t}}\right)$ resultam da função de poupança e de tecnologia da produção manufaturada. ${ }^{4}$ Nas hipóteses usuais relacionadas às formas funcionais (por exemplo, utilização de tecnologia de produção Cobb-Douglas), a função $D\left(K_{t}\right)$ é crescente e côncava. Portanto, no longo pra-

\footnotetext{
${ }^{2}$ Como na maioria dos modelos da geração imbricada, a expressão da restrição orçamentária intertemporal estabelece que a riqueza da família é igual ao salário corrente. As condições suficientes de segunda ordem são satisfeitas

${ }^{3}$ Essa igualdade entre estoque e fluxo é comum nesse tipo de modelo. Cf. demonstração em anexo.

${ }^{4}$ Igualando as produtividades marginais do trabalho, nos dois setores, obtem-se esse resultado.
} 
zo, a taxa de crescimento da riqueza converge rumo ao estado regular da economia. ${ }^{5}$

Resulta-se dessa função da dinâmica da economia uma segunda hipótese a ser testada.

H ipótese 2: Um acréscimo da insegurança fundiária produz um efeito positivo no crescimento econômico.

Mostrou-se na primeira hipótese que uma redução da insegurança fundiária $a_{\mathrm{t}}$ diminui o custo marginal de transações fundiárias, aumenta o preço da terra e modifica a composição da poupança que não será propícia ao capital empregado no setor manufaturado. Logo, o efeito de evicção perceptível, do capital pela terra, restringe a acumulação, aumenta a taxa de juros do estado regular da economia e penaliza, por conseguinte, o crescimento econômico.

Assim, de uma maneira geral, e respeitando a condição de arbitragem, todo choque exógeno, que acresce a rentabilidade antecipada da atividade agrícola, prejudica a acumulação e o crescimento econômico. Portanto, uma política agrária que visa reduzir a violência rural e/ou aumentar a produtividade marginal da terra reduzindo a dimensão das parcelas rurais, por exemplo, terá um impacto positivo na rentabilidade do setor agrícola porém negativa no crescimento.

Drazen \& Eckstein (1988) estabelecem um resultado similar no caso onde o mercado fundiário é inexistente e a terra concentrada nas mãos de um número limitado de grandes proprietários que a transmitem de geração a geração. Esses autores mostram que o aumento do número de proprietários fundiários reduz o nível do capital da economia no estado regular. Aliás, a ausência do mercado fundiário produz maiores acumulações do capital. Esse resultado pode ser assimilado a um caso limite de nosso modelo onde $a_{t}$ é bastante elevado e impede a comercialização de terras.

\section{ANÁLISE ECONOMÉTRICA EM DADOS DE PAINEL DO MODELO A “GERAÇÃO IMBRICADA”}

O modelo teórico compreende duas hipóteses que são testadas em um modelo econométrico utilizando dados de painel. Esse modelo utiliza uma hipótese auxiliar relativa à medida da insegurança fundiária apresentada abaixo. Em seguida, são apresentados a amostra, o método de estimação e os resultados obtidos.

\footnotetext{
${ }^{5}$ Eaton (1987) demonstra as condições suficientes nas quais um estado regular existe quando o estoque de capital é estritamente positivo. Admite-se portanto a inexistência de um equilíbrio de fronteira em que a poupança seria integralmente utilizada para aquisições fundiárias.
} 


\section{H ipótese complementar: Avaliação aproximativa da insegurança fundiária pelo número de ocupantes}

No Brasil, a insegurança rural é estreitamente ligada ao nível elevado da concentração fundiária e à luta dos trabalhadores rurais pelo acesso à terra. Com efeito, a herança brasileira de um passado colonial cuja estrutura fundiária foi fortemente concentrada, apresenta hoje um coeficiente de Gini de 0,850 (no ano de 2000), sendo assim um dos países onde a desigualdade da distribuição de terras é a mais importante no mundo. ${ }^{6}$

O modelo histórico de ocupação de terras é baseado em latifúndios controlados por oligarquias rurais próximas do poder político. $\mathrm{Na}$ segunda metade do século XIX, a introdução de títulos de propriedade fundiária pelo Império ("Lei de Terras”) permite aos latifundiários a obtenção de maiores poderes, enquanto que os pequenos camponeses, que não possuem nenhum meio para adquirir a terra, tornam-se ocupantes ilegais. Dessa legislação fundiária, origina-se, por conseguinte, uma categoria de trabalhadores rurais sem terra, os posseiros, que cultivam terras nas quais eles não são proprietários legais. A "Lei de Terras" reforçou também o fenômeno de grilagem de terras, no qual os fazendeiros-grileiros se apropriavam de terras devolutas cultivadas por camponeses, através da falsificação de documentos, subornos dos responsáveis pela regularização fundiária e assassinatos de trabalhadores. Dessa maneira, as fazendas cultivadas pelos camponeses sem terras eram apossadas pelos coronéis (Mançano Fernandez, 2001). Os movimentos de expropriação se multiplicaram no início do século XX, essencialmente com a instalação de sociedades multinacionais e o desenvolvimento de infra-estruturas ferroviárias e rodoviárias.

$\mathrm{Na}$ metade do século XX aparecem formas organizadas de resistência contra a expropriação e de luta pela terra (Ligas Camponesas, União dos Lavradores e Trabalhadores Agrícolas - ULTAB, Movimento dos Agricultores Sem-Terra - Master ...) sob égide da igreja católica ${ }^{7}$ e do partido comunista. As Ligas Camponesas e os sindicatos dos trabalhadores rurais organizaram ocupações de terras, primeiro no Sul e em seguida, no remanescente do país. Porém, o golpe militar, em 1964, aniquila provisoriamente esses movimentos camponeses.

Apesar da promulgação do Estatuto da Terra, realizado no mesmo ano do golpe militar, e que constitui o primeiro projeto de reforma agrária (Lei ${ }^{\circ} 4.504$, de 1964), a redistribuição fundiária foi um grande malogro com poucos assentamentos realizados até o final do período militar em 1984 (cf. figura 1). ${ }^{8}$ Além disso, durante os anos 60 e 70 a agricultura brasileira passa por fases de moderni-

\footnotetext{
${ }^{6}$ Fonte: INCRA, Cadastro de Imóveis Rurais. Para um histórico do direito agrário no Brasil cf. Marques (1998).

${ }^{7}$ Em 1975, a igreja católica criou a Comissão Pastoral da Terra (CPT), que articulou os novos movimentos camponeses que insurgiram durante o regime militar (cf. Mançano Fernandes, 2001).

${ }^{8}$ Segundo os dados da CPT e do MST, foram instaladas, entre 1964 e 2000, 700.239 famílias, com a seguinte repartição: 77.465 entre 1964 e 1984, 140.568 entre 1985 e 1994 e 482.206 entre 1995 e 2000 (cf. site do mst)
} 
zação que beneficia principalmente os latifúndios e consolida o processo de concentração fundiária pela absorção de minifúndios pelas médias e grandes propriedades. Segundo os dados do IBGE, o coeficiente de Gini de repartição da terra passou de 0,731 em 1960 à 0,867 em 1975.

Porcentagem da famílias instaladas nos processos de distribuição agrária, Brasil, 1964-2000

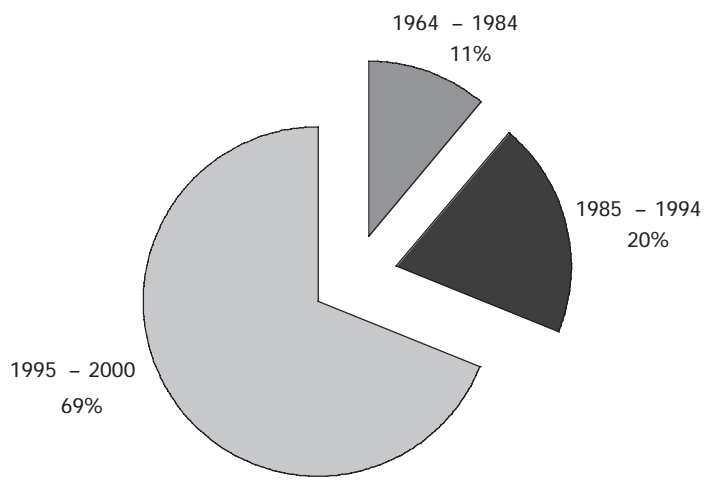

Fonte: Comissão Pastoral da Terra (CPT) e Movimento dos Trabalhadores Rurais Sem Terra (MST).

A resistência contra a expropriação e a luta pelo acesso à terra se intensificam a partir de 1984 (fim do período militar) com a criação do Movimento dos Trabalhadores Rurais Sem Terra (MST) e a multiplicação das ocupações de terras nos estados do Sul, em São Paulo e no Mato Grosso do Sul. Todavia, as ações dos sem-terras permitem uma aceleração do processo de reforma agrária somente a partir de 1995 (figura 1), pois um aumento significativo do número de assentamentos é realizado. Com efeito, durante o período 1995 - 2000, o número de famílias instaladas representa aproximativamente $70 \%$ do número total de instalações realizadas entre os anos 1964 e 2000.

Nota-se também que a luta pela terra nos anos 80 conduziu provavelmente a um forte aumento dos conflitos fundiários (cf. figura 2). Outrossim, o processo de assentamentos realizados nos anos 90 contribuiu para a redução do número de assassinatos no meio rural. ${ }^{9}$

Desde 1920, os censos agropecuários do IBGE contabilizam o número de ocupantes, fornecendo assim uma imagem da evolução do fenômeno de ocupação de terras. Os ocupantes estão presentes em todos os estados brasileiros. Eles cultivam ilegalmente as terras que pertecem a proprietários privados, a institui-

\footnotetext{
${ }^{9} \mathrm{O}$ problema dos assassinatos no campo pode ser, também, associado ao desempenho da economia, ou seja, quando a economia está num processo de crescimento, há maiores oportunidades de emprego e, em conseqüência, redução de desempregados e das invasões de terra, resultando assim em decréscimo do número de assassinatos no campo. Os autores agredecem as observações dos parecistas sobre esse ponto. Para um maior aprofundamento da relação entre criminalidade e crescimento econômico, cf. Fajnzylber e alli (2002).
} 
Figura 2. Assassinatos de trabalhadores rurais relacionados aos conflitos fundiários, Brasil, 1964 - 2000

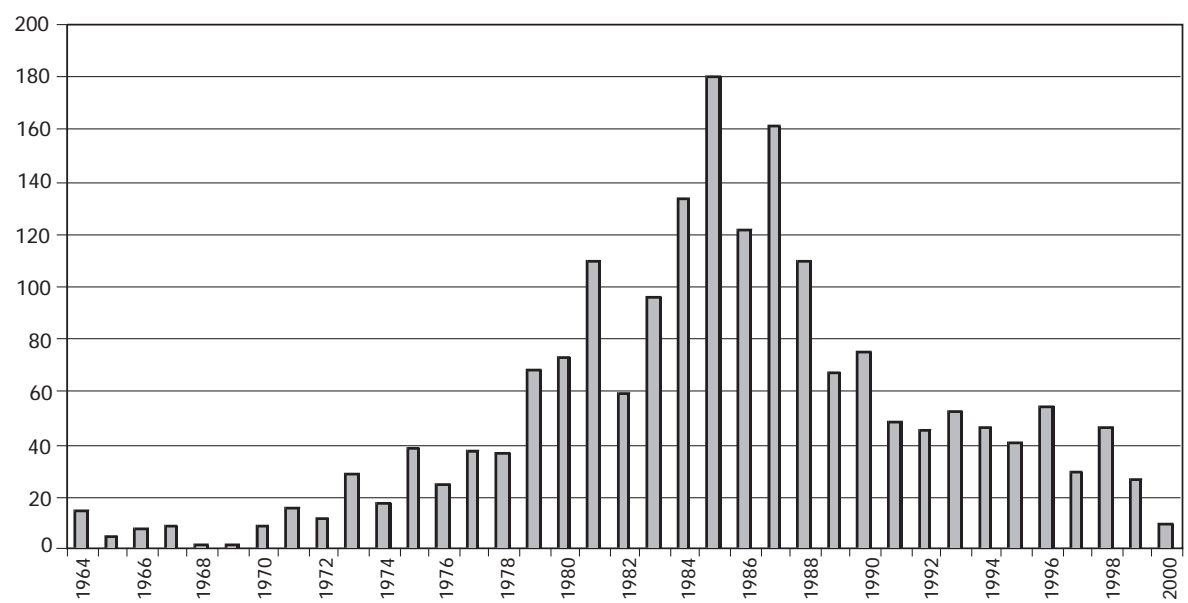

Fonte: CPT e MST.

ções religiosas ou ao Estado (cf. figura 3). Eles são particularmente importantes nos estados menos ricos do Brasil (regiões Norte e Nordeste), onde eles ocupam aproximativamente $20 \%$ dos imóveis rurais contra 4 e $7 \%$ no Sul e Sudeste respectivamente. Os estados do Centro-Oeste estão numa posição intermediária em termos de renda e de acesso a terra. Após um forte crescimento entre 1970 e 1975 , que corresponde à expansão da fronteira agrícola, a proporção de ocupantes tende a diminuir, passando de, aproximativamente, 25\% em 1975 a 12\% em 1996. Enquanto que, durante o mesmo período, o número de propriedades privadas passou de 60\% em 1975 a 77\% em 1996, segundo os censos agropecuários.

Paralelamente, o número de imóveis rurais em arrendamento e parcerias é relativamente baixo e descrescente. Ele representa $10 \%$ do total das propriedades rurais em 1996 contra 17\% em 1970. Essa baixa porcentagem de contratos agrícolas é, sem dúvida, conseqüência da insegurança dos direitos de propriedade. Os proprietários não são predispostos a instalar nas suas terras um arrendatário ou parceiro suscetível de empenhar-lhe mais tarde um direito de propriedade. Além disso, a legislação fundiária que prevê a expropriação e a redistribuição das terras devolutas instiga à partição fictiva da propriedade entre os membros da família e contribui a insegurança dos direitos de propriedade (Araujo \& Araujo Bonjean, 1999).

A evolução do número de ocupantes, avaliados em porcentagem do número total de imóveis rurais, é utilizado neste trabalho como uma variável proxy da insegurança fundiária. Assim, como mostra a história brasileira, a presença de ocupantes é, ao mesmo tempo, a origem e a conseqüência da insegurança fundiária. Por um lado, a invasão de terras pelos ocupantes conduz a um risco de desapropriação para os proprietários. Por outro lado, a imperfeita definição dos direitos de propriedades (lacuna do ordenamento jurídico agrário) incita a apropriações ilegais de terras (cf. balanço das grilagem na página na internet do Incra). 
Figura 3. Imóveis rurais ocupados ilegalmente em porcentagem do número total de propriedades agrícolas, Brasil e regiões, 1970 - 1996

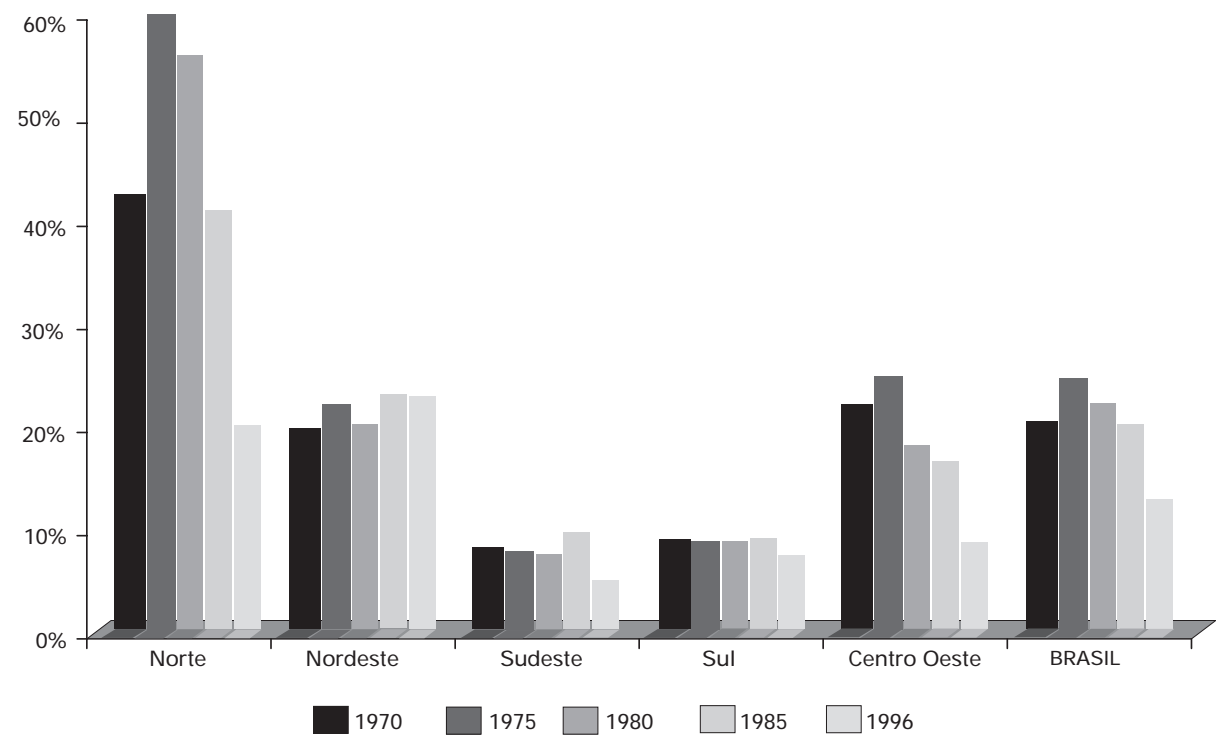

Fonte: IBGE.

\section{A amostra e o método de estimação}

O modelo é estimado em dados de painel compreendendo uma dimensão temporal e uma individual. ${ }^{10}$ A primeira é composta de seis períodos $(1970,1975$, 1980, 1985, 1990, 1995); a segunda é constituída pelas 27 unidades, atuais, da federação. O painel é, assim, potencialmente composto de 162 dados. ${ }^{11}$ Esta dupla dimensão permite o controle das heterogeneidades não observadas, seja individuais como temporais.

Por razões associadas aos desmembramentos e fusão de certos estados, assim que a inexistência de alguns dados necessários nesse estudo, o painel é in-

\footnotetext{
${ }^{10}$ As fontes dos dados utilizado nesse estudo são diversas: Instituto Brasileiro de Geografia (ocupantes, superfície), Fundação Getúlio Vargas (preços produtos, insumos e terra), Instituto de Meteorologia (pluviometria) e Instituto de Pesquisa Econômica Aplicada (PIB, esperança de vida, anos de estudo).

${ }^{11}$ Cabe salientar que, atualmente, o Brasil é composto de 26 estados mais o Distrito Federal. Essa repartição geográfica não corresponde a todo o período da análise. Efetivamente, somente a partir de 1988 o Brasil passa a ter 26 estados. Nos anos 70 o Brasil contava com 22 estados e três territórios (Rondônia, Roraima e Amapá) que se elevaram à categoria de estado nos anos 80 (1981, 1988 e 1988 respectivamente). Houve também durante o período da análise fusão e desmambramentos de estados. Houve fusão no caso do Rio de Janeiro e Guanabara (1975) e desmambramentos no caso do Mato Grosso em 1977, que foi dividido em dois estados (Mato Grosso e Mato Grosso do Sul) e no caso do Goiás em 1988 (Goiás e Tocantins). Para uma melhor homogeneidade dos dados considerase 27 UF.
} 
completo (unbalanced panel). ${ }^{12} \mathrm{~A}$ utilização de dados incompletos conduz geralmente a problemas de heterocedasticidade nos modelos de painel, portanto as estimações não são eficientes. A dificuldade consiste assim em obter estimadores eficientes para as variâncias individuais e a variância da perturbação estocástica. As equações estimadas (cf. tabelas 1 e 3 ) levam em conta a técnica de correção conveniente para o cálculo dessas variâncias. ${ }^{13}$

O modelo é estimado pelos mínimos quadrados de dois estágios (MQ2E). Três razões justificam o recurso às variáveis instrumentais. Primeiro, neutralizar o viés de simultaneidade; segundo, se proteger contra o viés de atenuação que é devido a erros de medida nas variáveis explicativas; e terceiro, se precaver contra as conseqüências de omissão de variáveis pertinentes correlacionadas com as variáveis explicativas.

As estatísticas de Student e os erros de primeira espécie foram corrigidos da heterocedasticidade pelo método de White (1980). As equações estimadas foram submetidas a diferentes testes de especificação (cf. tabelas 2 e 4). A estatística de Nakamura - Nakamura (1981) testa o caráter exógeno das variáveis explicativas com relação aos erros "idiossincráticos". ${ }^{14} \mathrm{O}$ teste de superidentificação de Sargan (1988) avalia a qualidade dos instrumentos e, em particular, a ortogonalidade destes com relação ao resíduo. Essas estatísticas garantem que os instrumentos são pertinentes (Araujo, Brun \& Combes, 2004). O teste do RESET de Ramsey (1969) indica a pertinência da forma funcional. ${ }^{15}$

\section{Teste econométrico da hipótese 1: insegurança fundiária e preço da terra}

Conforme a equação do rendimento do ativo fundiário dado pela equação (7a), espera-se que um aumento do número de ocupantes, variável proxy da insegurança fundiária, conduza uma redução do preço da terra. Essa hipótese é testada utilizando duas especificações do modelo de determinação do valor fundamental da terra: ${ }^{16}$ a primeira está relacionada às variáveis de teste (ocupantes e

\footnotetext{
${ }^{12}$ Nota-se que na medida do possível, utiliza-se dados retrospectivos das unidades da federação ainda não criadas durante o período da análise, mas calculados pelo IBGE com base nos dados municipais, micro-regionais e meso-regionais. Assim, é possível reconstituir os dados não observados ao nível estadual, mas observados somente ao nível municipal, e recompor a série estatística do estado em questão.

${ }^{13} \mathrm{cf}$. Baltagi, 2005.

${ }^{14} \mathrm{O}$ teste de Nakamura-Nakamura é uma versão simplificada do teste de Durbin, Wu, Hausman. Na prática, o teste é realizado em duas etapas. Na primeira etapa, a variável endógena do modelo é estimada em função dos instrumentos pelos mínimos quadrados ordinários (MQO); calcula-se assim o resíduo. Na segunda etapa, introduz-se esse resíduo no modelo principal e estima-se pelos MQO. Utiliza-se assim a estatística do t de student para realizar o teste. Se dúvidas persistem sobre outras variáveis explicativas, ou seja, se outras variáveis são consideradas como endógenas, o teste pode ser generalizado. Nesse caso, deve-se utilizar a estatística do F (Fisher-Snedecor) para realizar o teste. Rejeita-se a heterogeneidade, se a variável de teste é significativa.

${ }^{15}$ As variáveis de teste são as variáveis explicativas estimadas introduzidas ao quadrado, ao cubo e à quarta potência.
} 
aluguel da terra), e a segunda se refere às variáveis de controle (preço dos produtos e insumos, pluviometria ${ }^{17}$ e superfície da propriedade).

$\mathrm{Na}$ primeira estimação (equação 1, tabela 1), o produto marginal da terra é avaliado pelo aluguel em $\mathrm{R} \$$ constante por hectares; espera-se um efeito positivo (e. g. Roche \& McQuinn, 2001; Lence \& Miller, 1999; Engsted, 1988).${ }^{18} \mathrm{Na}$ segunda estimação (equação 2, tabela 1) as variáveis determinando o lucro do estabelecimento agrícola foram introduzidas na equação do preço da terra, pois elas são correlacionadas com a produtividade marginal da terra (e.g. Roche \& McQuinn, 2001). Espera-se um efeito positivo do preço dos produtos e um efeito negativo do preço dos insumos e da superfície média do imóvel rural.

Tabela 1: Teste da hipótese 1

Variável dependente: preço real da terra

\begin{tabular}{|c|c|c|}
\hline & Equação 1 & Equação 2 \\
\hline Variáveis explicativas & $\begin{array}{c}\text { Coeficientes } \\
\text { (erros de } 1^{\text {a }} \text { espécie) }\end{array}$ & $\begin{array}{l}\text { Coeficientes } \\
\text { (erros de } 1 \text { à espécie) }\end{array}$ \\
\hline Aluguel $(\mathrm{R} \$ / \mathrm{ha})$ & $1,066(0,001)$ & \\
\hline Ocupantes $\left(n^{\circ}\right)$ & $-1,042(0,000)$ & $-0,905(0,000)$ \\
\hline Preço do arroz ( $\mathrm{R} \$ / \mathrm{ha})$ & & $0,914(0,002)$ \\
\hline Preço da mandioca (R\$/ha) & & $0,372(0,024)$ \\
\hline Preço do milho (R\$/ha) & & $-0,202(0,217)$ \\
\hline Preço do fumo (R\$/ha) & & $0,093(0,372)$ \\
\hline Preço da eletricidade $(R \$ / k w)$ & & $-0,226(0,338)$ \\
\hline Preço do querosene $(\mathrm{R} \$ / \mathrm{l})$ & & $-0,259(0,408)$ \\
\hline Pluviometria (mm) & & $0,004(0,321)$ \\
\hline (Pluviometria)_(mm) & & $-0,000(0,202)$ \\
\hline Superfície (ha) & & $-0,326(0,052)$ \\
\hline Controle da heterogeneidade individual & Dummies regionais & Dummies regionais \\
\hline Controle da heterogeneidade cronológica & Tendência temporal & Tendência temporal \\
\hline $\mathrm{R}^{2}$ ajustado & 0,640 & 0,749 \\
\hline Variáveis endógenas & Aluguel e ocupantes & Ocupantes \\
\hline Número de observações & 72 & 87 \\
\hline
\end{tabular}

As variáveis estão avaliadas em logaritmo.

${ }^{16}$ Vários estudos em economia agrícola procuram testar a relação entre o preço da terra e sua rentabilidade (e.g. Falk \& Lee, 1998). Pode-se também citar o trabalho de Alston, Libecap \& Schneider (1996), que procura mostrar o efeito dos direitos de propriedade sobre o valor da terra no caso dos estados do Pará e do Paraná.

${ }^{17}$ A pluviometria ao quadrado permite levar em conta o excesso de chuva.

${ }^{18}$ O IGP-DI publicado pela FGV foi utilizado como deflator para o cálculo de todos os preços em valor constante. 


\section{Lista das variáveis instrumentais:}

Equação 1: preços do arroz, do algodão, do milho, do fumo, da eletricidade, do querosene, dos pesticidas, pluviometria, variável ocupantes defasada (o período anterior é 1960), coeficiente de Gini da distribuição de terras, superfície média da propriedade rural.

Equação 2: variável ocupantes defasada, coeficiente de Gini da distribuição de terras e todas variáveis exógenas do modelo.

Independentemente da especificação utilizada (equações 1 e 2 ), a variável teste de ocupantes tem o sinal negativo esperado. Nota-se, além disso, que a relação entre ocupantes e o preço da terra é bastante forte, assim que entre aluguel e preço da terra, pois as respectivas elasticidades são unitárias. A equação 2 (equação de controle) apresenta, de uma maneira geral, os resultados esperados: sinais positivos para os preços dos produtos e pluviometria; e sinais negativos para os preços dos insumos, pluviometria ao quadrado e superfícies. ${ }^{19}$

O resultado associado à variável superfície sustenta diversos trabalhos realizados na literatura econômica. Com efeito, considera-se geralmente que os minifúndios são mais eficientes que os latifúndios (Junqueira Assunção, 2003). Essa afirmação é baseada na "relação inversa" entre o tamanho da propriedade rural e a produtividade da terra; a produtividade total é, por conseguinte, decrescente (Binswanger \& alli, 1995). ${ }^{20}$

Os testes relacionados às equações 1 e 2 são apresentados na tabela 2 . $O \mathrm{R}^{2}$ ajustado da equação auxiliar corresponde ao $R^{2}$ da primeira fase do MQ2E. O resultado obtido (valor do $\mathrm{R}^{2}$ ) mostra que os instrumentos são pertinentes. $\mathrm{O}$ teste de Nakamura-Nakamura (tabela 2) não invalida a hipótese de ausência de dependência das variáveis aluguel e ocupantes. ${ }^{21}$ Os testes econométricos são pertinentes (Sargan, Reset e Jarque-Bera), principalmente o teste de Sargan, que garante a qualidade dos instrumentos utilizados. Esse teste é pertinente somente se o número de variáveis instrumentais é superior ao número de variáveis endógenas.

\footnotetext{
${ }^{19}$ Cabe salientar que a introdução conjunta de vários preços de produtos e de insumos ocasiona problemas de multicolinearidade imperfeita. Por conseguinte, a interpretação dos coeficientes é um pouco sutil.

${ }^{20}$ Esse resultado é encontrado, de uma maneira geral, em vários trabalhos empíricos, inclusive no caso do Brasil (cf. Araujo, 1999). Entretanto, cabe salientar que o desempenho da produção depende também do tipo de cultivo e das características físicas das propriedades. Assim, certas culturas, analisadas individualmente, podem apresentar resultados que contradizem a "relação inversa". Isso se explica pela existência de rendimentos crescentes de escala, devido à utilização de máquinas agrícolas e ao progresso técnológico.

${ }^{21} \mathrm{Na}$ equação 2, o teste de Nakamura-Nakamura rejeita a hipótese de exogeneidade da variável ocupantes, no limite de confiança de $19 \%$. Esse valor é superior aos limites estatísticos habitualmente utilizados nos trabalhos empíricos. Contudo, afim de prevenir contra todo viés na estimação, a variável é instrumentada.
} 
Tabela 2:

Testes econométricos relativos à hipótese 1

\begin{tabular}{lll}
\hline & Equação 1 & Equação 2 \\
\hline $\mathrm{R}^{2}$ ajustado auxiliar & $0,79^{\mathrm{a}} \mid 0,55^{\mathrm{b}}$ & $0,84^{\mathrm{a}}$ \\
\hline Nakamura - Nakamura & $\mathrm{F}=2,96(0,059) \mathrm{c}$ & $\mathrm{t}=1,33(0,19)^{\mathrm{d}}$ \\
\hline Sargan $\left(\chi^{2}\right)$ & $12,17(0,204)$ & $0.065(0,798)$ \\
\hline Reset $(\mathrm{F}$ teste) & $0,93(0,43)$ & $1,263(0,294)$ \\
\hline J arque-Bera $\left(\chi^{2}\right)$ & $1,17(0,56)$ & $1,48(0,477)$ \\
\hline
\end{tabular}

Entre parênteses: probabilidade de rejeição (erros de 1aㅡ espécie).

a: $R^{2}$ da primeira fase do MQ2E da equação auxiliar para a variável ocupantes.

b: $R^{2}$ da primeira fase do MQ2E da equação auxiliar para a variável aluguel de terras.

c: $\mathrm{F}$ teste para o conjunto das duas variáveis endógenas ocupantes e aluguel.

$\mathrm{d}$ : t teste para a variável endógena ocupantes.

\section{Teste econométrico da hipótese 2: insegurança fundiária e crescimento econômico}

Segundo a hipótese 2, o respeito da condição de arbitragem favorece os investimentos produtivos se a rentabilidade antecipada da atividade agrícola diminui. Como as lutas pelo acesso à terra aumentam os custos de transação, diminuindo por conseguinte a rentabilidade antecipada na atividade agrícola, o impacto do aumento dos ocupantes no crescimento econômico será positivo. Essa hipótese é testada através um modelo econométrico de $\beta$-convergência condicional.

$\mathrm{O}$ modelo de $\beta$-convergência condicional é o equivalente econométrico do modelo de Solow. Espera-se, ceteris paribus, um impacto negativo do PIB per capita inicial sobre a taxa de crescimento por causa, principalmente, da existência de rendimentos de escala decrescentes. O modelo mostra, assim, que as regiões mais pobres convergem mais rapidamente ao estado regular da economia que as regiões mais ricas. O estado regular é função também de outras variáveis do modelo que controlam o estado regular da economia (e.g. Barro \& Sala-I-Martin, 2003), em particular os ocupantes. Utiliza-se as variáveis de controle, proxy da dotação em capital humano, seguinte: esperança de vida ao nascer e número médio de anos de estudo para a população na faixa etária superior a 25 anos.

O resultado econométrico, apresentado na tabela 3, identifica o fenômeno de convergência condicional. O PIB do início do período influencia negativamente o crescimento econômico, enquanto que as variáveis de capital humano têm um impacto positivo e significativo. A variável ocupantes, como esperado, tem um impacto positivo no crescimento econômico.

O impacto do PIB per capita inicial é forte (elasticidade aproximativamente igual a 0,2) comparado a outros estudos empíricos (cf. Barro \& Sala-I-Martin, 1992; Mankiw, Romer \& Weil, 1992). Entretanto, como mostra Islam (1995 e 1998), a utilização de uma estrutura em dados de painel produz resultados dife- 
rentes de estudos utilizando dados em corte transversal. O coeficiente da convergência condicional é geralmente maior no caso do painel. Da mesma maneira, o valor das elasticidades da produção com relação às variáveis de capital é geralmente menor no caso do painel. Com efeito, nota-se que o impacto no crescimento econômico da variável "anos de estudo" é pouco robusto. O impacto da variável esperança de vida é aproximativamente equivalente aos ocupantes.

Tabela 3: Teste da hipótese 2

Variável dependente: taxa de crescimento do PIB per capita

\begin{tabular}{lc}
\hline & Equação 3 \\
\hline Variáveis explicativas & Coeficientes (erros de 1a espécie) \\
\hline PIB per capita inicial & $-0,196(0,012)$ \\
Esperança de vida & $0,231(0,055)$ \\
Anos de estudo & $0,077(0,179)$ \\
Ocupantes & $0,272(0,076)$ \\
\hline Controle da heterogeneidade individual & Efeitos fixos individuais \\
\hline $\mathrm{R}^{2}$ ajustado & 0,289 \\
Variáveis endógenas & Ocupantes \\
Número de observações & 154 \\
\hline
\end{tabular}

As variáveis do PIB e do capital humano estão em logaritmo.

As variáveis do modelo consideradas como exógenas são: a esperança de vida, o número médio de anos de estudo. Os instrumentos do modelo são: o produto defasado (1960), a variável ocupantes defasada (1960), o coeficiente de Gini, a superfície média da propriedade e as variáveis exógenas.

A introdução da taxa de juros, elemento do custo de oportunidade do capital investido, avaliado pela taxa de base bancária (deflacionado), comum a todos os estados, não é significativa e não altera a influência das outras variáveis.

Os testes econométricos da equação de crescimento econômico são apresentados na tabela 4. O resultado obtido para o $R^{2}$ ajustado da equação auxiliar $(0,79)$ e o teste de Sargan mostram que os instrumentos são pertinentes. O teste de Nakamura-Nakamura não invalida a hipótese de ausência de dependência da variável ocupantes. O teste Reset valida a forma funcional do modelo.

Tabela 4: Testes econométricos relativos à hipótese 2

\begin{tabular}{lc}
\hline $\mathrm{R}^{2}$ ajustado auxiliar & $0,79 \underline{a}$ \\
\hline Nakamura - Nakamura (t teste) & $4,483(0,013)$ \\
\hline Sargan $\left(\chi^{2}\right)$ & $2,167(0,705)$ \\
\hline Reset $(\mathrm{F}$ teste) & $0,110(0,856)$ \\
\hline
\end{tabular}

Entre parênteses: probabilidade de rejeição.

a: $R^{2}$ da primeira fase do MQ2E da equação auxiliar para a variável ocupantes.

b: As variáveis de teste são as variáveis explicadas estimadas introduzidas ao quadrado e ao cubo. 


\section{IMPLICAÇÕES PARA A POLÍTICA FUNDIÁRIA}

Os resultados econométricos não infirmam as duas hipóteses estabelecidas neste trabalho: a insegurança fundiária diminui a demanda de terras favorecendo assim o crescimento econômico através redução do preço da terra. Vê-se assim, que o mercado fundiário está relacionado ao crescimento econômico no caso do Brasil. As lacunas do ordenamento jurídico agrário acarretam conseqüências macro-econômicas.

Evidentemente, a insegurança fundiária não pode ser uma situação socialmente ótima, pois ela causa efeitos externos negativos (violência, crimes, conflitos...). Não obstante efeitos positivos da insegurança no crescimento, uma reforma fundiária gera benefícios sociais importantes.

Logo, afim de não penalizar o crescimento, as reformas não deveriam privilegiar a distribuição dos direitos de alienação (abusus), porém favorecer a distribuição de direitos de usufruto (usus-fructus). Ou seja, o objetivo central da reforma fundiária deveria ser a garantia dos direitos de propriedade, de tal forma que ela seja favorável ao desenvolvimento do mercado de locação de terras que é atualmente pouco dinâmico. Segundo o último censo agrícola, somente $2,4 \%$ das terras são arrendadas.

A amplificação do mercado de locação de terras não conduz a efeitos de evicção do capital produtivo e deve ser preferido a programas que resultam em uma maior demanda de terras. Num contexto cujos direitos de propriedade estão garantidos, o instrumento fiscal (taxas nas mais-valias, exoneração fiscal de alugueis, etc.) torna-se mais conveniente para favorecer o desenvolvimento do mercado de locação.

\section{ANEXO: EQUILÍBRIO GERAL NO PERÍODO T}

Considera-se nessa economia que os mercados de bens e do serviço de segurança fundiária estão em equilíbrio:

$$
\begin{array}{ll}
\left(x_{1, t}^{m}+x_{2, t}^{m}\right) L+\left(K_{t+1}-K_{t}\right)=M_{t} \quad \text { equilíbrio do setor manufaturado } \\
\left(x_{1, t}^{a}+x_{2, t}^{a}\right) L+\frac{\partial C_{t-1}}{\partial T} p_{t-1} T=A_{t} \quad \text { equilíbrio do setor agrícola }
\end{array}
$$

$\mathrm{X}^{\mathrm{m}}$ e $\mathrm{X}^{\mathrm{a}}$ representam respectivamente o consumo do bem manufaturado e do bem agrícola, $x^{m}+X^{a}=X$. A expressão $(\partial C / \partial T) p_{t} T$ representa o valor da produção de um serviço anexo de garantia fundiária no setor agrícola que é consumido por ambas gerações: "jovens" ou "antigos". Pode-se interpretar o custo marginal de transação como o preço desse serviço. 
Deduz-se o equilíbrio macroeconômico emprego-recursos global:

$$
\left(x_{1, t}+x_{2, t}\right) L+K_{t+1}-K_{t} \frac{\partial C_{t-1}}{\partial T} p_{t-1} T=M_{t}+A_{t}
$$

Na hipótese de retornos constantes de escala nas funções de produção setoriais e utilizando as condições de maximização do lucro (equações (5), (6), (7) e (8)), obtém-se:

$$
\left(\mathrm{x}_{1, \mathrm{t}}+\mathrm{x}_{2, \mathrm{t}}\right) \mathrm{L}+\mathrm{K}_{\mathrm{t}+1}-\mathrm{K}_{\mathrm{t}} \frac{\partial \mathrm{C}_{\mathrm{t}-1}}{\partial \mathrm{T}} \mathrm{p}_{\mathrm{t}-1} \mathrm{~T}=\mathrm{w}_{\mathrm{t}} \mathrm{L}+\mathrm{r}_{\mathrm{t}} \mathrm{K}_{\mathrm{t}}+\left(\left(1+\mathrm{r}_{\mathrm{t}}\right) \mathrm{p}_{\mathrm{t}-1}-\mathrm{p}_{\mathrm{t}}+\frac{\partial \mathrm{C}_{\mathrm{t}-1}}{\partial \mathrm{T}} \mathrm{p}_{\mathrm{t}-1}\right) \mathrm{T}
$$

Reorganizando essa expressão, a fim de mostrar as restrições orçamentárias dos consumidores no período presente, resulta:

Após simplificações, chega-se ao seguinte resultado:

$$
\mathrm{K}_{\mathrm{t}+1}+\mathrm{p}_{\mathrm{t}} \mathrm{T}=\left(1+\mathrm{r}_{\mathrm{t}}\right)\left(\mathrm{K}_{\mathrm{t}}+\mathrm{p}_{\mathrm{t}-1} \mathrm{~T}\right)-\mathrm{x}_{2, \mathrm{t}} \mathrm{L}
$$

Se $\left(K_{t}+p_{t-1} T\right)=S_{t-1} L$ então $\left(K_{t}+p_{t-1} T\right)=s_{t-1} L$

\section{REFERÊNCIAS BIBLIOGRÁFICAS}

ALSTON, L. J., G. D. LIBECAP \& R. SCHNEIDER, 1996, “The determinants and impact of property rights: Land titles on the Brazilian frontier", J ournal of $L$ aw, Economics and O rganization. Volume $12, \mathrm{n}^{\circ} 1$, pp: 25-61.

ALSTON, L. J., G. D. LIBECAP \& B. MUELLER, 1999, "A model of rural conflict: violence and land reform policy in Brazil", Environment and D evelopment Economics. Volume 4, n 2, pp:135-160.

ARAUJO, C., 1999, "Reforma agrária: base teórica e realidade brasileira", in Aguiar D. \& J.B. Pinho, A nais do XXXVII Congresso Brasileiro de Economia e Sociologia R ural. Brasília: SOBER.

ARAUJO, C. \& C. ARAUJO Bonjean, 1999, "Mesure de l'efficacité des modes de faire valoir au Brésil”, Canadian Journal of A gricultural E conomics. Volume 47, pp: 181-97.

ARAUJO, C., J.-F. BRUN \& J.-L. COMBES, 2004, Econométrie. Paris: Bréal.

BALTAGI, B., 2005, E conometric analysis of panel data, $3^{\text {a }}$ edition, New York, John Wiley.

BANERJEE, A. \& M. Ghatk, 2004, "Eviction Threats and Investment Incentives”, J ournal of D evelopment Economics, Volume 74, 2, pp: 469-88.

BARRO, R.J. \& X. Sala-I-Martin, 2003, Economic growth. $2^{\text {nd }}$ edition: Ediscience internationale, McGraw-Hill.

BINSWANGER, H.P., K. DEININGER \& G. Feder, 1995, "Power, Distorsions, Revolt and Reform in Agricultural Land Relations”, in J. Behrman \& T.N. Srinivasan (Eds.), H andbook of D evelopment Economics. Amsterdam: Elsevier. Volume III.

BIRDSALL, N. \& J.L. LONDONO, 1997, “Asset Inequality Matters: an Assessment of the World Bank's Approach to Poverty Reduction”, World Bank Economic Review. Volume 87, 2, pp: 32-37.

BRASSELLE, A.-S., F. GASPART \& J.-P. Platteau, 2002, "Land Tenure Security and Investment Incentives: Puzzling Evidence from Burkina Faso", J ournal of D evelopment Economics, Volume: 67, 2, pp: 373-418.

DEATON, A. \& G. LAROQUE, 2001, "Housing, Land Prices, and Growth", J ournal of Economic Growth. Volume 6, pp: 87-105.

DE JANVRY, A., G. GORDILLO, J.P. Platteau \& E. Sadoulet, 2001, Access to L and, R ural Poverty and Public Action, Oxford University Press. 
DEININGER, K., 1999, “Making Negociated Land Reform Work: Initial Experience from Colombia, Brazil and South Africa”, World D evelopment. Volume 27, 4, pp: 651-72.

DEININGER, K., 2003, L and Policies for G rowth and Poverty Reduction, World Bank Policy Research Report, Oxford University Press and World Bank.

DEININGER, K. \& L. Squire, 1998, "New Ways of Looking at Old Issues: Inequality and Growth", J ournal of D evelopment E conomics. Volume 57, pp: 249-87.

DIAMOND, P., 1965, "National Debt in a Neoclassical Growth Model”, A merican Economic Review. Volume 55, pp: 1126-50.

DRAZEN, A. \& Z. ECKSTEIN, 1988, "On the Organization of Rural Markets and the Process of Economic Development”, American Economic Review. Volume 78, 3, pp: 431-43.

EATON, J., 1987, “A Dynamic Specific-Factors Model of International Trade”, R eview of Economics Studies, Volume 54, 2, pp: 325-38.

ENGSTED, T., 1998, “Do Farmland Prices Reflect Rationally Expected Future Rents ?”, A pplied E conomics L etters, Volume 5, pp: 575-79.

FAJNZYLBER, P. D. LEDERMAN \& N. LOAYZA, 2002, "What causes violent crime?”, European Economic Review, Volume 46, pp: 1323-57.

FALK, B. \& B.S Lee, 1998, "Fads Versus Fundamentals in Farmland Prices", A merican Journal of Agricultural Economics. Volume 80, pp: 696-707.

INCRA, 2005, http://www.incra.gov.br/_htm/serveinf/_htm/pubs/pubs.htm, página: serviços e informções - publicações.

ISLAM, N., 1995, "Growth Empirics: A Panel Data Approach”, The Q uarterly Journal of Economics, Volume: 110, 4, pp: 1127-1170.

ISLAM N., 1998, “Growth Empirics: A Panel Data Approach — A Reply”, The Q uarterly Journal of Economics, Volume: 113, 1, pp: 325-29.

JUNQUEIRA, Assunção J., 2003, "Distribuição de terra e as políticas públicas voltadas ao meio rural brasileiro", in Brazil: Inequality and economic development in Brazil. Washington DC: Workd Bank. Volume II.

JUNQUEIRA, Assunção J. \& M. Ghatak, 2003, "Can Unobserved Heterogeneity in Farmer Ability Explain the Inverse Relationship between Farm Size and Productivity", Economic L etters, Volume: 80,2 , pp: $189-94$.

LENCE, S.H. \& D.J. Miller, 1999, "Transaction Costs and the Present Value Model of Farmland: Iowa, 1990-1994", A merican J ournal of A gricultural Economics, Volume 81, pp: 257-72.

MANÇANO, Fernandes B., 2001, "Brasil: 500 anos de luta pela terra”, Revista de Cultura Vozes, março (www.culturavozes.com.br/revistas/0293.html).

MANKIW, N. D. ROMER \& D. Weil, 1992, “A Contribution to the Empirics of Economic Growth, Q uarterly J ournal of E conomics, Volume 107, pp: 407-37.

MARQUES, B. F., 1998, D ireito A grário Brasileiro. Goiânia: AB editora, Segunda edição.

MST, 2005, http://www.mst.org.br/biblioteca/bibliotec3dados.htm, página: biblioteca — mst em dados.

NAKAMURA, A. \& M. Nakamura, 1981, "On the Relationships Among Several Specification Error Tests Presented by Durbin, Wu and Hausman", Econometrica. Volume 49, pp: 1583-88.

PERSSON, T. \& G. Tabellini, 1992, "Growth, Distribution and Politics”. Reprinted from: The Political Economy of Business Cycles and G rowth, Cukierman, A. e alii (eds). Oxford: MIT Press.

RAMSEY, J., 1969, “Tests for Specification Errors in Classical Linear Least Squares Regression Analysis", J ournal of the Royal Statistical Society. Série B, Volume 31, pp: 350-71.

ROCHE, M.J. \& K. McQuinn, 2001, "Testing for speculation in agricultural land in Ireland", European Review of A gricultural Economics. Volume 28, 2, pp: 95-115.

SAMUELSON, P. A., 1958, "An Exact Consumption-Loan Model of Interest with or without the Social Contrivance of Money”, J ournal of Political Economy. Volume 66, 6, pp: 467-82.

SARGAN, J.D., 1988, "Testing for Misspecification after Estimating Using Instrumental Variables", in E. Maasoumi, ed., Contributions to E conometrics: J ohn D enis Sargan, 1. Cambridge: Cambridge University Press.

WHITE H., 1980, “A Heteroskedasticity-Consistent Covariance Matrix Estimator and a Direct Test for Heteroskedasticity”, E conometrica. Volume 48, pp: 817-38. 